\title{
On the thermo-mechanical events during friction surfacing of high speed steels
}

\author{
G.M. Bedford $^{\mathrm{a}, *}$, V.I. Vitanov ${ }^{\mathrm{b}}$, I.I. Voutchkov ${ }^{\mathrm{c}}$ \\ ${ }^{a}$ Department of Mechanical and Manufacturing Engineering, University of Portsmouth, Anglesea Road, Anglesea Building, \\ Portsmouth PO1-3DJ, UK \\ ${ }^{\mathrm{b}}$ Building 30, School of Industrial and Manufacturing Sciences, Cranfield University, Cranfield, Bedfordshire MK43-OAL, UK \\ ${ }^{\mathrm{c}}$ CEDC, School of Engineering Sciences, University of Southampton, Highfield, Southampton SO17-1BJ, UK
}

Received 31 July 2000; accepted in revised form 1 March 2001

\begin{abstract}
This paper is concerned with the friction surfacing of high-speed steels, BM2, BT15 and ASP30 onto plain carbon steel plate. The events that the matrix and carbides experience as the coating material pass from the coating rod to the substrate, in forming the coating, is described. The coating is observed to harden automatically within a few seconds of being deposited onto the cold substrate. This autohardening is observed to be an inherent feature of the friction surfacing process and the only post-coating heat treatment required is tempering, as with traditionally hardened high-speed steels. The mechanism of autohardening is discussed in terms of the mechtrode/coating/substrate thermal system. (c) 2001 Elsevier Science B.V. All rights reserved.
\end{abstract}

Keywords: Friction surfacing; Hardfacing; High speed steels

\section{Introduction}

High-speed steels were introduced at the beginning of this century. The process used to produce them involves casting and rolling which results in coarse, inhomogeneous arrays of carbides that do not bring out the best in this class of steels. In the second half of the century, however, there have been considerable efforts devoted to other methods of processing high speed steels to produce fine, homogeneous arrays of carbides embedded in a high alloy martensitic matrix. The ASP family of high-speed steels was developed in Sweden in the 1960's and is now widely used. As Fig. 1a,b prompts, they possess the following properties in comparison to conventional high speed steels:

\footnotetext{
* Corresponding author.
}

- a higher hardness, higher content of elements forming carbides;

- a higher toughness, the material is free from carbide segregation; and

- isostropic properties, the material exposes a structure with an even distribution of carbide particles in the matrix phase.

ASP steels have solved the problem of the heterogeneous distribution of carbides by using a powder route instead of the traditional casting and rolling route, however, they still require the traditional heat treatment. More recently, other suppliers have developed high-speed steels, also using powder routes, in which fine homogeneous arrays of carbides are generated, e.g. Böhler, Austria.

In the past decade, a coating method for high speed steels has been developed, Fig. 2a,b in which as- 


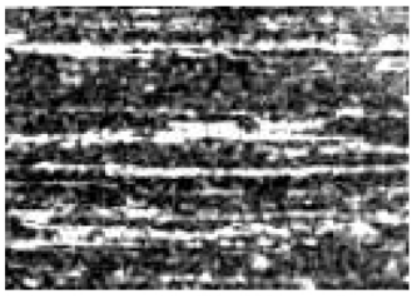

a)

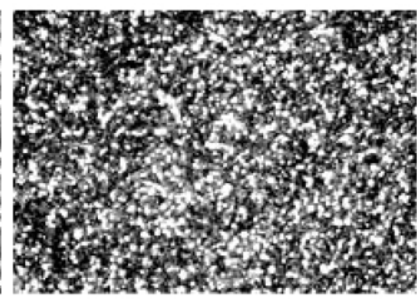

b)
Fig. 1. Conventional high-speed steel (a) and ASP family high-speed steel (b).

deposited high speed steel not only has the fine distribution of carbides achieved by powder routes, such as ASP, but is also in the fully hardened state requiring only tempering in the manner used for traditionally hardened steels. Details of the friction surfacing process can be found elsewhere [1-6].

The work in this paper describes the coating process and the use of microscopy, heat treatment and hardness testing to study the events that the material undergoes as it moves from the coating mechtrode, through the interfacial zone onto the substrate. The effect of tempering on the hardness of the coating is also determined. In this paper, 'mechtrode' is used as a term for the involved coating rod, which is being consumed during the process.

\section{Experimental development and procedure}

Experiments using a range of mechtrode diameters,

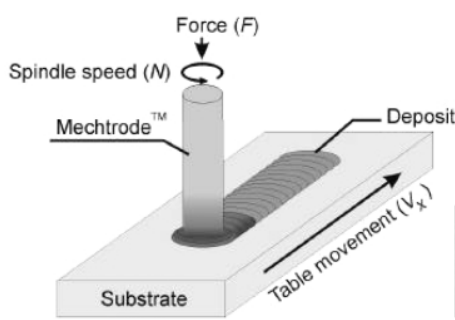

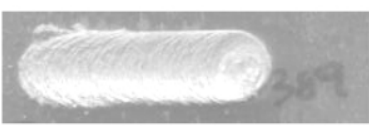

b)
Fig. 2. (a) Principle of friction surfacing and (b) plain view of coating using a 5-mm diameter mechtrode.

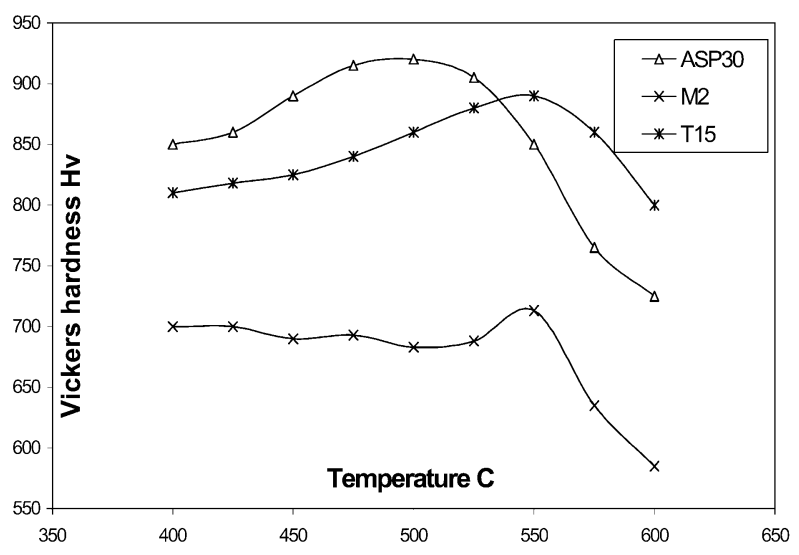

Fig. 3. Tempering curves $2 \times 1 \mathrm{~h}$ of T15, M2 and ASP30.

from 5 to $32 \mathrm{~mm}$, were carried out at Frictec Ltd on a commercial machine and also on a research machine at the University of Portsmouth. The friction surfacing process parameters for three high-speed steels Table 1, were optimised using an approach described elsewhere [7]. Plain carbon steel plate was used for the substrates.

Heat treatment of samples was carried out with the temperatures controlled to $1^{\circ} \mathrm{C}$. Vickers hardness testing was conducted on ground surfaces, cleaned using emery paper after each tempering treatment. The metallography was carried out on both plan and crosssections in both as polished and etched conditions. The study of the morphology and composition of the carbides at different stages of the progress from coating rod to coating is currently in its early stages and will be published in the near future.

\section{Results}

Fig. 3 shows the results of tempering the different high-speed steels in the upper temperature range $350-600^{\circ} \mathrm{C}$. The hardness profile of the heat affected zones was also measured and these are shown as Fig. 4. Fig. 5 compares a hardness profile of a friction surfaced deposit with an arc welded deposit and a microstructure identifying the carbides in the BM2 coating (see Fig. 6).

Table 1

BT15, BM2 and AMT 30 compositions with forging and austenitising temperatures

\begin{tabular}{llllllrlr}
\hline $\begin{array}{l}\text { High speed } \\
\text { steels }\end{array}$ & $\mathrm{C}$ & $\mathrm{W}$ & $\mathrm{Mo}$ & $\mathrm{Cr}$ & $\mathrm{V}$ & $\mathrm{Co}$ & $\begin{array}{l}\text { Forging } \\
\text { range }(\mathrm{EC})\end{array}$ \\
\hline BT15 & $1.4-1.6$ & $12-13$ & $0-1.0$ & $4.25-5.0$ & $4.75-5.25$ & $4.5-5.5$ & $982-1177$ \\
range $\left({ }^{\circ} \mathrm{C}\right)$
\end{tabular}




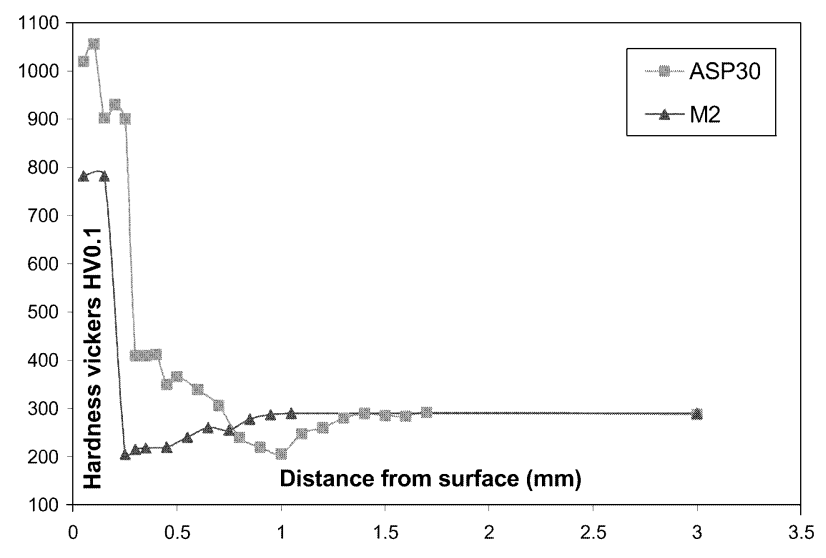

Fig. 4. Heat affected zones of M2 and ASP30.

\section{Discussion}

An inherent feature of friction surfacing is the autohardening of high-speed steels such that only tempering remains to be carried out after coating. The tempering curves Fig. 3, show the familiar secondary hardening shape before rapidly losing hardness above $550^{\circ} \mathrm{C}$, in common with traditionally hardened and tempered high-speed steels. A further important feature of friction surfacing is the consistency of the autohardening as illustrated in Fig. 4. The hardness has almost an order of magnitude improvement in consistency over the fusion welding based coating process and this is important in ensuring that properties are constant along the length. This is particularly valuable in products such as machine knives used in the processing and packaging industries when cutting life and scheduled tooling changes are an important cost in the process.

The heat affected zone in the substrate is localised and can be seen (Fig. 4) to be less than $0.5 \mathrm{~mm}$ into the substrate. This is significantly different from many other surfacing processes based on fusion and laser processes in which the whole component reaches elevated temperatures. In the case of friction surfacing, only localised heating occurs and the overall component, although becoming 'hot', does not reach elevated temperatures and hence affects the properties of the substrate deleteriously.

The coating/substrate bond is essentially formed by a diffusion bonding mechanism. The micrograph in Fig. 6 indicates the different types of carbides that form in BM2. The mechanism of transfer involves the material being removed from the mechtrode and rolling over onto the substrate.

In considering the thermo-mechanical events during friction surfacing Fig. 7a,b,c serves to show how coating material transfers from mechtrode to substrate. Fig. 7a is a cross-section of the process showing the principle of the coating system and Fig. 7c is a detail of Fig. 7a and shows how the rubbing interface separates mechtrode material from the material that forms the coating. As the substrate draws across the face of the rotating mechtrode the material at the rubbing interface will either go towards developing the flash or will form the coating. The coating immediately beneath the mechtrode will experience temperatures in the region of $1020^{\circ} \mathrm{C}$ until forced into contact with the cold substrate when heat transfer occurs across the coating/substrate boundary and the bond is formed. The diffusion bond is a result of the force applied to the mechtrode together with the heat generated at the rubbing interface.

The depth of the HAZ is a function of the temperature at the coating/substrate interface and the time at temperature, i.e substrate speed. The cold substrate causes rapid cooling resulting in the transformation of

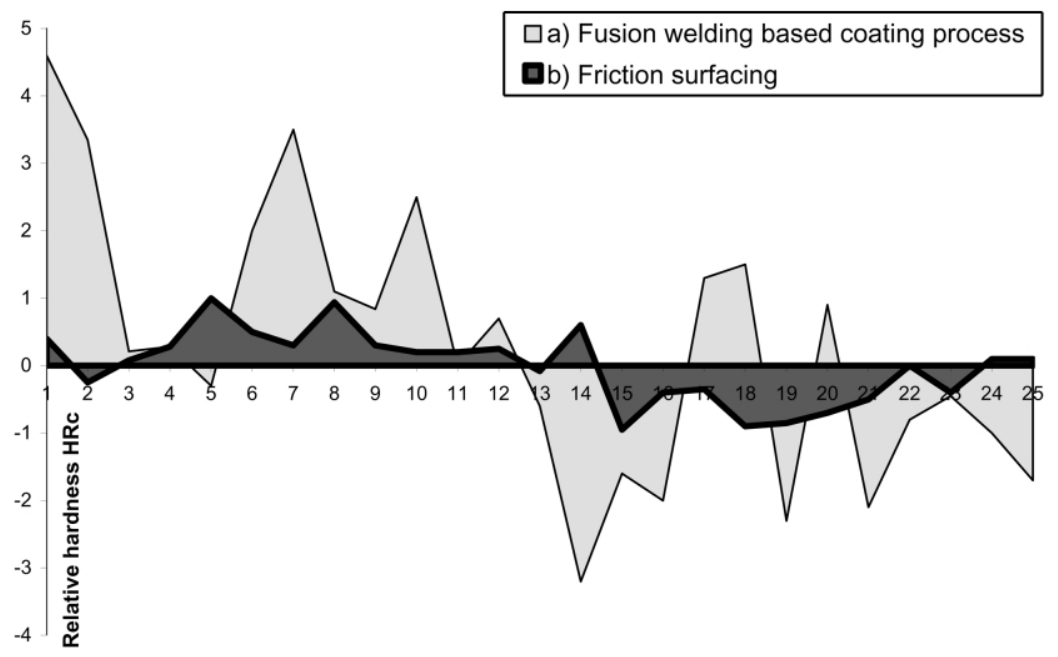

Fig. 5. Hardness variance profile along $250-\mathrm{mm}$ length of high speed steel deposit in the tempered condition of (a) fusion welding based surfacing process $\pm 4 R \mathrm{c}$ and (b) friction surfaced $\pm 1 R \mathrm{c}$. 


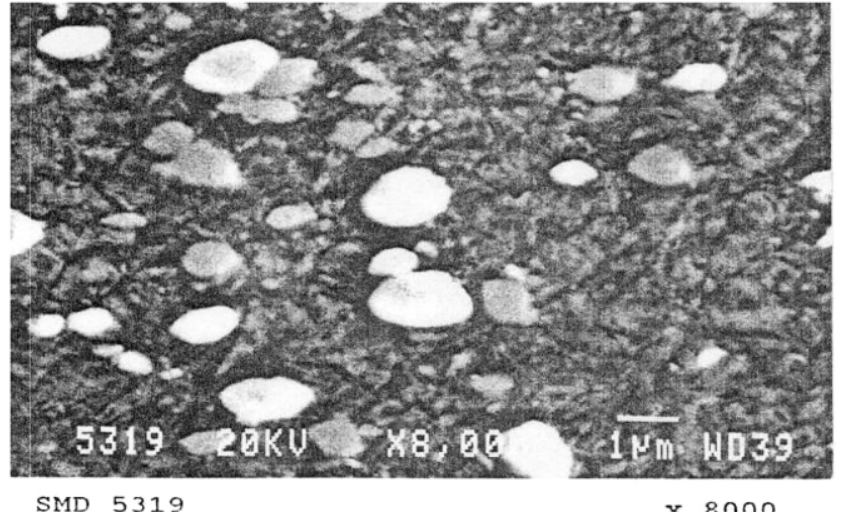

SMD 5319

x 8000

Fig. 6. Microstructure of M2 coating, consisting of tempered martensite and carbides: $\mathrm{M}_{6} \mathrm{C}$ (white); and $\mathrm{MC}$ (gray).

austenite to martensite. As can be seen from the photograph Fig. $7 b$, the whole coating is cooled to the temperature of the substrate within a few seconds of being deposited, which indicates a rate of cooling in excess of $400^{\circ} \mathrm{C} / \mathrm{s}$. The effect of the friction surfacing process is not only to take the carbides into solution, but also to cause some mechanical effects, possibly fracture of the carbides, before being cooled rapidly. A study of austenitic 316 stainless steel, indicated that a very fine grained austenite structure is retained at room temperature and this suggests that it is likely the austenite in high-speed steels will be refined due to the thermomechanical effects of the rubbing interface and that the martensite will be formed from fine austenite and, hence become fine martensite, which will have optimum properties following tempering.

In terms of the austenitising kinetics of the friction surfacing process it is the mechtrode diameter that plays a significant role. Fig. 8 shows a plan view of the coating and the elliptical area of the actual mechtrode
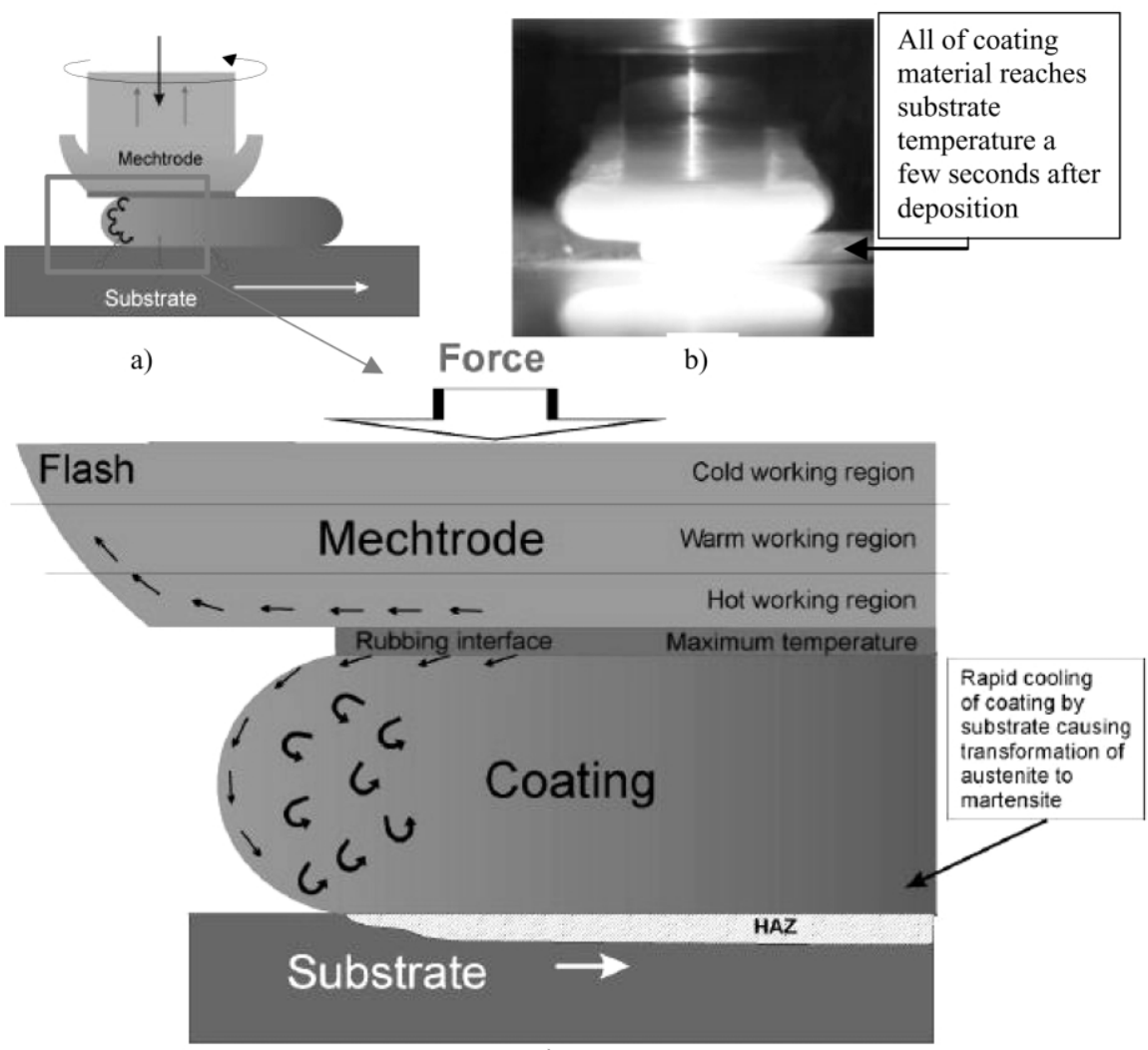

c)

Fig. 7. (a,b and c) Thermomechanical events during friction surfacing transfer of coating material to substrate.

Austenitising time is given by
\[ t_{a}=\frac{6}{7} \frac{\sqrt{M_{d}^{2}-4 d_{c}^{2}}}{V_{x}}, \]
where $V x$ is traverse speed,
$M d$ is mechtrode diameter, $d c$ is
distance from centre

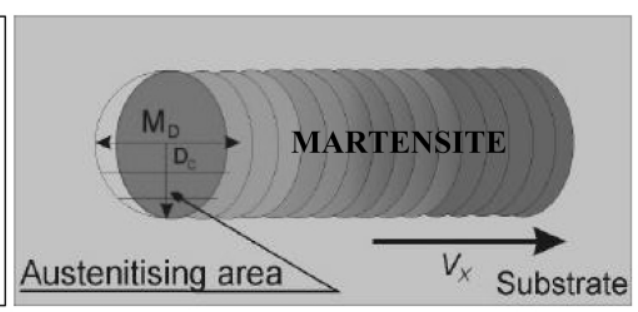

Fig. 8. Austenitising times of high speed steel as a function of mechtrode diameter and substrate speed. 


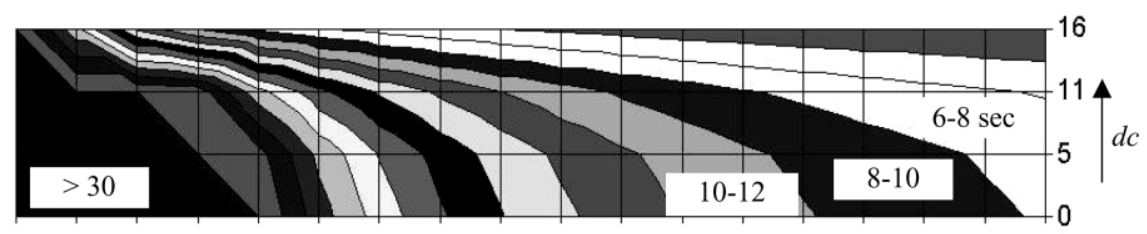

(a)

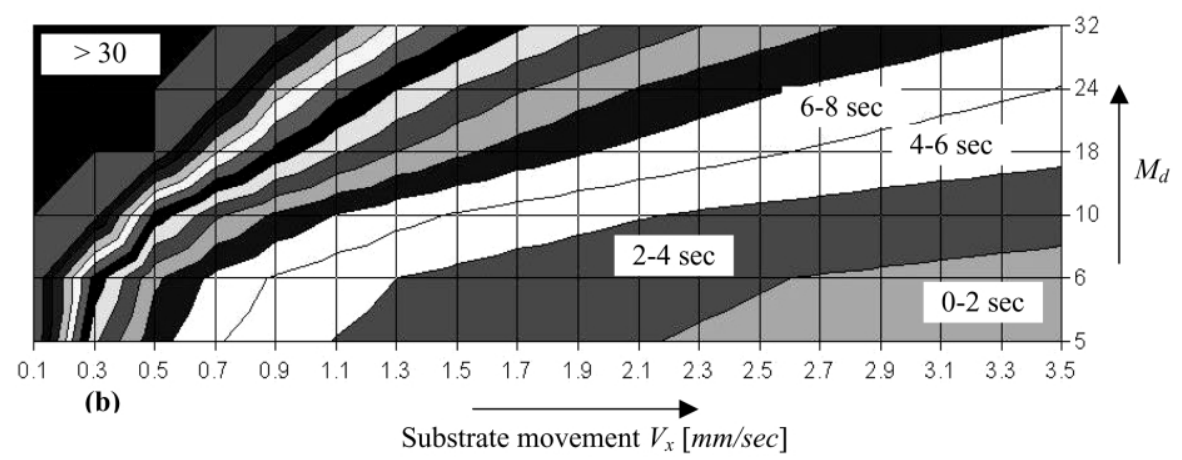

Fig. 9. Time spent at elevated temperatures in austenitizing region as a function of traverse speed ( $V x$ ) (a) radial positions (d.c.) for a 32-mm diameter mechtrode and (b) time spent by central region of coating for given mechtrode diameters $(M d)$.

rubbing region. The graph of temperature vs. time in Fig. 9a,b shows that along the diameter of the mechtrodes, say 32 and $10 \mathrm{~mm}$, moving at $1 \mathrm{~mm}$ per second, the region under the mechtrode experiences, 32 and $10 \mathrm{~s}$ of maximum temperature, respectively, before cooling. Regions at radial distances have proportionally less time at maximum i.e. austenitising temperature. Therefore, it may be expected that there could be some differences across the coating. It is expected that such an effect would likely become more evident at larger diameters, say $18 \mathrm{~mm}$ and above. Experiments are currently being conducted to study this aspect. Fig. 9b indicates the given austenitising times for given diameters at various substrate speeds.

The conventional thermal cycle for high-speed steels is shown as Fig. 10. The thermal cycle for friction surfacing shows a rapid increase in temperature due to rapid development of the rubbing interface temperature and the hot working occurring at the rubbing interface. The time spent at the elevated temperature is a function of the mechtrode diameter. The coating is rapidly cooled immediately it leaves the rubbing interface and this leads to the autohardening of the coating. A $1+1 \mathrm{~h}$ tempering treatment is then applied in the traditional manner.

\section{Conclusions}

1. An inherent feature of friction surfacing is the occurrence of autohardening of high-speed steels such that only a post-coating tempering treatment remains to be carried out.

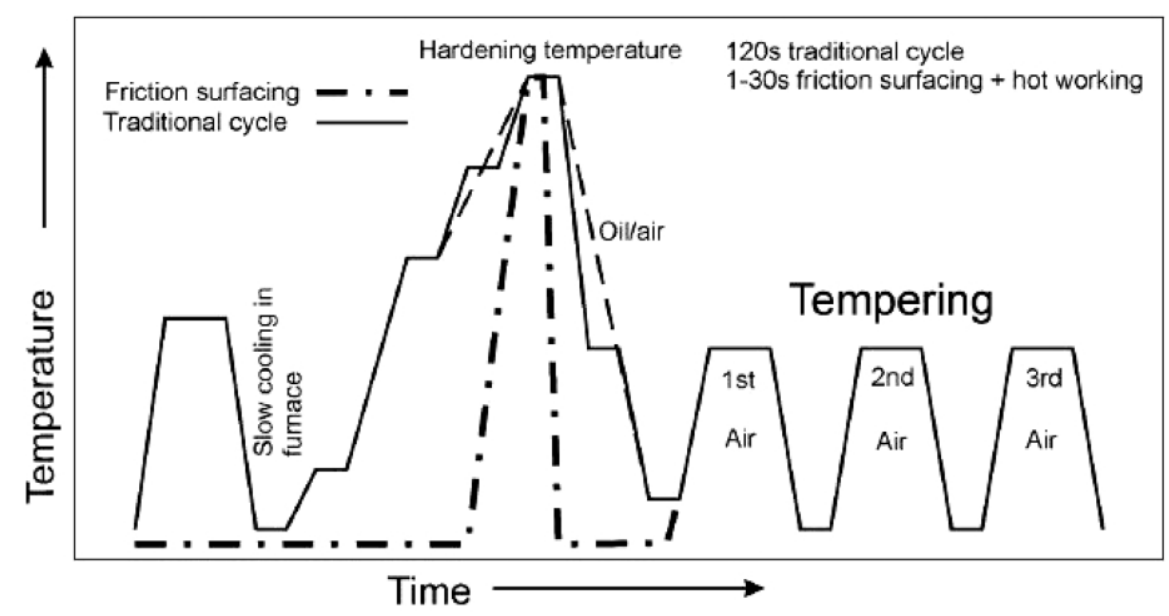

Fig. 10. Traditional heat treatment cycle of high speed steels and friction surfacing thermal cycle followed by traditional tempering. 
2. There are indications that secondary hardening is occurring during tempering in common with traditionally hardened and tempered high-speed steels.

3. The temperature at the rubbing interface has been measured to be $1020^{\circ} \mathrm{C}$.

\section{Acknowledgements}

The authors would like to express their thanks to Frictec Ltd for use of equipment and the supply of materials.

\section{References}

[1] Bedford G.M., Ward L.J., Tooley P.J., Wilson B.J., Sharp R.J., Large scale friction surfacing EUROMAT, 4th European Con- ference on Advanced Materials and Processes, Italy, Sept., 1995, pp. 441-444

[2] Bedford G.M., Davies A., Sharp J.R., Micro-friction surfacing in the manufacture and repair of gas turbine blades, Third International Charles Parsons Turbine Conference, Newcastle, April, 1995, pp 683-693

[3] G.M. Bedford, Friction Surf. Wear Appl, Metal Mater. 6 (11) (1990) 702-705.

[4] T. Shinoda, Q. Li, Y. Katoh, T. Yashiro, Effect of process parameters during friction coating on properties of non-dilution coating layers, Surf. Eng. 14 (3) (1998) 211-216.

[5] Thomas W.M., Solid phase cladding by friction surfacing, Welding for the process industries, April, 1988, pp.101-119

[6] Groupe ERASTEEL - web page

[7] Voutchkov I., Vitanov, V., Bedford G.M, An integrated approach to friction surfacing process optimization, International Conference on Advances in Materials and Processing Technologies AMPT 1999, Dublin, Ireland 